\title{
Critical Review of Dust in the Mining Environment: A Focus on Workers and Community Health
}

\author{
Brian Chanda Chiluba*1.23 \\ ${ }^{1}$ The University of Zambia, School of Health Sciences PO Box 50110, Lusaka, Zambia \\ ${ }^{2}$ The University of Zambia, School of Mines, Lusaka, Zambia \\ ${ }^{3}$ The University of Cape Town, Cape Town, South Africa \\ *Corresponding Author: Brian Chanda Chiluba \\ Email: babchiluba@yahoo.com
}

\section{ABSTRACT}

Dust inhalation is a huge concern in the mining environment and within all its operations. In fact, dust to be one of the most serious occupational hazards in the mining industry. Coal and crystalline silica dust are the causes of serious, sometimes fatal lung diseases such as pneumoconiosis, which affects coal miners, as well as silicosis, tuberculosis, chronic bronchitis, emphysema, chronic obstructive pulmonary disease, and chronic renal disease, which affect coal and other types of miners. The resulting effects both affect workers and nearby communities. The mining industry has in the past, employed several approaches to reduce effects of dust. But these strategies have often been ineffective because the grass withers during the dry season and sprayed water is rapidly absorbed or evaporates. This paper endeavors to review information on dust in the mining environment and how it is a nuisance to workers and communities and establish what strategies exist for this.

Key word: Dust, Mining, Environment, Sustainability, community health, occupational health

\section{Introduction}

During almost all mining activities there are various forms of activities from mining extraction to refinery that put the risk of workers and communities at risk due to dust from such activities that pollute the mining and nearby surrounding to endanger the health of those in close proximity mining environment $[1,2]$. Actually the most notable dust emissions are usually particulate matter $(\mathrm{PM})$, sulfur dioxide (SO2), nitrogen dioxide (NO2) and heavy metals and mostly these are suspended as dust in the mining environment. It should be noted that dust from mine environment is a very big issue as it deteriorate air quality and ultimately affect the human health, flora and fauna in and around coal mining areas [3]. 
The novella article, by Momoh et al., is a very explicit articles in terms of leveraging mining dust effects to human health both within mining environment and communities within their vicinities [4]. The article "Potential implications of mine dusts on human health: A case study of Mukula Mine, Limpopo Province, South Africa" published in 2013 is an important article because it is very comprehensive in establishing what dust particles are unacceptable by WHO standard.

The purpose of this study was to estimate levels of Suspended Particulate Matter in ambient air within mining environment and the potential risks to mineworkers and communities nearby. While the "Respiratory Diseases Caused by Coal Mine Dust" by Laney and Weissman is informative and insightful because the authors emphasizes a spectrum of respiratory diseases that affect miners as a results of dust from the mine environment termed as "coal mine dust lung disease" though the paper does not address the effects of mining dust on community living in close proximity, the main objective of the paper is to provide an update on respiratory diseases caused by coal mine dust.

The paper by Rey et al., in his paper "Underground Coal Mining: Relationship between Coal Dust Levels and Pneumoconiosis, in Two Regions of Colombia, 2014" published in 2015 observed that there was a high levels of coal dust and silica among the 29 companies that were sampled and that the prevalence of pneumoconiosis was much higher than what has been reported in other studies among mine workers [5]. Other studies focused on levels of dusts observed from small scale mining, like a study done by Bråtveit, Moen, Mashalla and Maalim in 2002 called "Dust Exposure During Small-scale Mining in Tanzania: A Pilot Study”. This paper discusses that there is actually more dust produced from small scale mining that what has been assumed and if the focus is only on economic strides this may make sustainable mining difficult. The objectives of this pilot study were to monitor the exposure to dust during work processes, which are typical of small-scale mining in developing countries, and to make a rough estimation of whether there is a risk of chronic pulmonary diseases for the workers [6]. Lastly a paper done by Önde in a paper published in "Investigation of Dust Levels in Different Areas of Underground Coal Mines". The paper found that levels of mining is too high and there is need to control these levels.

All in whole these papers do not seem to address what should be done in order to sustain mining in realm of workers and community people, but simply present merely the effects of dust from 
mining environments. Therefore the purpose of this review is to identify the gaps in the reviewed papers in light of sustainable development within the mining with respect to mining dust.

\section{Summary}

In the papers reviewed there will be failure if the papers do not critically examine the meaning of the concept and practice of sustainable development and mining in the contexts of dusts from mining environment and how this is very detrimental to the health of workers and communities. Discussing sustainable development in light of this is important because dust from mining environments is a nuisance to the communities and the workers themselves and hence the need to monitor dust fall out to keep it within the acceptable level that has a minimal impact on communities.

It should be stressed that Health and safety is always the first priority in the mining industry. It requires not only to provide a safe workplace for mining operations, but also to offer a safe and sustainable environment for the communities around the mine-site. Some of the pertinent issues form mining environment that arise during an entire mine life cycle include the following categories: general workplace health and safety and the hazardous substances such as dusts that come as a results of the processes of mining [7].

It should be understood that most if not all mining operations produce dust and this may result in various spectrum of health issues as far as the community is concerned and most importantly the health of workers e.g. chronic bronchitis/pneumoconiosis. Dust in the mining area could simply be viewed as particulates matters and this can be divided into TSP, PM10 and PM2.5. At the same time it is should well be understood that dust is generally measured in terms of weight of particles per cubic meter of air. There is an inherent and well understood association between mining activity and the resulting dust and this association is progressive in every step of mining operations. It should also be well noted that open cast mines produces more dust as compared to underground mines.

From the above rationale, the paper by Abuh et al., does highlight that mine are as a result of mining activities' and the paper explains the different and various constituents of dust, 
methodologically however the paper does not seem to provide much information on what methods of data collection were used as this could be important to understand the study findings. As far as dust and mining environment is concerned every paper to address this issue should endeavor to address both the workers and community impact of dust. This paper seem to shed much emphasis on community concerns as far as the effects of dust is concerned on their health compared to other papers. The study does not also provide a progressive way for control and monitoring of dust in mining environment in light of sustainable mining. At the same time the study seem to establish an important that exposure for a risk really dependent on the dust levels. While a study by Laney and Weismman states that the most important aspect which is the fact that mining is very important for community and global economies and for the advancement of welfare of workers and community living. The study strikes a balance unlike the other studies, that when addressing dust effects on environments and human health, it is important that the benefits are weighed against the risk because given any situation any mining operations will continue to provide dust, but what matters is the amount of dust that is generated and the levels and how they risk workers and community health as well as the environment. This study however just like the preceding study does not provide for mechanism of sustainable management of dust in mining environments to curtail on the impacts of dust on workers and human health. The study too only addresses the health of workers as far as dust is concerned and fails to addresses the proximity of dust effects on communities [8]

Rey et al., study addresses coal dust mining and its effects on environment within mines and beyond. This was study was methodologically meaningful in proving reliable and valid results and this is because it was carried out as cross sectional analytical interventional study with the use of instruments to measure amount of dust in mining environment as well as the effects of dust on the workers and this was not merely dependent on other studies reports. The study also did establish one important factors that the other studies seem to fail to addressee and that is the past medical history of workers. This important as other workers smoke and are exposed to other pollutants other than that which come from the mines. This is an important investigation as the findings of a study could be confounded by any other exposure that inherently exist among those that work in the mines [5]. 
A study by Bratveit et al., despite all the other studies collecting information on large scale mining, this study established that actually there is more dust production from small scale mining and that this should be given the attention it deserves too. This study, unlike all the other study established that actually just a moderate exposure is a risk for health related issues within the mining environment. This study instead of just focusing on what is already the narrative of the scientific community on dust within the mining environments, the authors of this study went on further to physically monitor exposure to dust in small scale mining. There is no mention of community health in this study and this important if we have to understand the effects of dust on mining environments.

Lastly a study by Onder, is methodologically robust among all the studies because this study made use of records of dust measurements in the mining environment since the 1978 until 2006. This could be helpful to understand the trends in dust production over the years. Thus information could be utilized to come up with sustainable workable measures that could address the growing concern of dust in mining. However, this study does no conclusively and comprehensively reports on the findings of such reviews. One feature that seem to fall short in the studies is the mention of an intersectoral approach when doing mining [10]. A study by Billig et a' suggest that an intersectoral approach involving community, governmental and nongovernmental agencies, and the management of the mining firm. And from this study it appears success was achieved using this approach in addressing dust from the mining environment $[9,10]$

\section{Conclusions}

This section looks briefly the conclusion of dust in the mining environment and its health dynamics among workers and communities. What is important in this review should be what is needed to address the imbalance within the mining environment moving forward and implications for worker, community health and sustainability. This is quiet important because even when a mine is gone, the men and women who have worked in the mine may continue to experience health impacts for many years. The evidence of long-term impacts of mining on health of workers and communities is important in the context of sustainable development. These impacts imply that the mining sector's activities currently undermine the human objectives of sustainable development, which are to protect the health of current and future generations. This is despite the industry's role 
in economic development in the short term. Miners and the communities living around mines have fought hard for improvements to their health conditions over many years. This has resulted in great improvements in largescale formal mining where organized labor has worked with government and management to improve worker health and safety. Communities have also fought to gain health improvements and reduce health risks associated with living near mines.

\section{Statement of Competing Interests}

This paper has not been published elsewhere, and the author take responsibility and severally over the information provided therein. The author have no competing interests.

\section{Acknowledgements}

The authors would like to express their profound gratitude to the two anonymous reviewers who made wonderful suggestions to shape this final work. Special thanks also go to the University of Zambia, School of Mines who through the EDSA program made this work publishable. Thanks also to Dr. Jewet Masinja for the support and encouragement.

\section{References}

1. Baldauf, R.W., Lane D.D., \& Marote, G.A. (2001). Ambient air quality monitoring network design for assessing human health impacts from exposures to air-borne contaminants, Environmental Monitoring and Assessment, Vol. 66, pp. 63-76.

2. Collins, M.J., Williams P.L, \& MacIntosh, D.L (2001). Ambient air quality at the site of a former manufactured gas plant. Environmental Monitoring and Assessment Vol. 68, pp. 137-152.

3. Singh, A. 2007. Revegetation of coal-mine spoils using Prosopis juliflora in Singrauli coalfield is a harmful practice from an ecological viewpoint. Correspondence, Current Science 93: 1204.

4. Momoh A, Mhlongo SE, Abiodun O, Muzerengi C, Mudanalwo M. Potential implications of mine dusts on human health: A case study of Mukula Mine, Limpopo Province, South Africa. Pak J Med Sci 2013;29(6):1444-1446. doi: http://dx.doi.org/10.12669/pjms.296.3787

5. Rey, C.H, Pinilla,M.I, Ayala, L.B, Guerrero,D.M.C,Torres, G.M., Restrepo, HG and Uribe, M.V. (2015). Underground Coal Mining: Relationship between Coal Dust Levels and Pneumoconiosis, in Two Regions of Colombia, 2014; BioMed Research International Volume 2015, Article ID 647878, 8 pages http://dx.doi.org/10.1155/2015/647878

6. Bråtveit, M., Moen, B.E., Mashalla Y.J.S, and Maalim, H., (2002) Dust Exposure during Small-scale Mining in Tanzania: A Pilot Study; Ann. occup. Hyg., Vol. 47, No. 3, pp. 235240,DOI: 10.1093/annhyg/meg027 
7. IFC, International Finance Corporation. Environmental (2012). Health, and Safety Guidelines for Mining, 44-55.

8. Laney, S., and Weissman, D.N., (2014). Respiratory Diseases Caused by Coal Mine DusT; J Occup Environ Med. October; 56(0 10): S18-S22. doi:10.1097/JOM.0000000000000260

9. Billig, P., E. Gurzau, et al. (1999). Innovative intersectoral approach reduces blood leads levels of children and workers in Romania. Int J Occup Environ Health 5(1): 50-6.

10. Mustafa Önder, Seyhan Önder, Tuncay Akdag \& Firat Ozgun (2009) Investigation of Dust Levels in Different Areas of Underground Coal Mines, International Journal of Occupational Safety and Ergonomics, 15:1, 125-130, DOI: $10.1080 / 10803548.2009 .11076794$ 